Computer Optics and Nanophotonics

\title{
Vibration resistance of headlight design for electric locomotive
}

\author{
Abulkhanov S.R. \\ Samara State Aerospace University
}

\begin{abstract}
I determined the natural frequencies of the headlight design for electric locomotive VL by software system of the finite-element analysis ANSYS. The obtained values of the natural frequencies are compared with the frequencies of the periodic vibrations experienced by the railway rolling stock. The analysis reveals the vibration frequencies determining the period of the trouble-free operation of the headlight.
\end{abstract}

Keywords: headlight, electric locomotive, natural frequencies of design, trouble-free service life, periodic vibration, noise and re-emitted noise.

Citation: Abulkhanov SR. Vibration resistance of headlight design for electric locomotive. Proceedings of Information Technology and Nanotechnology (ITNT-2015), CEUR Workshop Proceedings, 2015; 1490: 112-121. DOI 10.18287/1613-0073-2015-1490-112-121

\section{Introduction}

The main sources of vibration for driving railway locomotive are just a vehicle, wheels, rails and railway track. According to the Resolutions of 15.07.2011, N 710 "On the adoption of the technical regulations of the Customs Union" ("On the safety of the railway rolling stock", "On the safety of the high-speed railway transport", and "On the safety of the railway infrastructure") [1], the range of vibration frequency causing the damage to structures (buildings) is from 1 to $500 \mathrm{~Hz}$, and the greatest damage to structures is at the low-frequency vibrations (the frequencies from 1 to $150 \mathrm{~Hz}$ ).

A railway locomotive undergoes periodic and random vibrations. The reasons of the excitation of the periodic vibrations are the deflection of the rail track moving along with the movement of the train and the support system; the discrete structure of the rail support (the distance between the axes of sleepers); the discreteness of the effect on the object due to the distance between the axes of wheel pairs and bogies; the breaks of the rail track (at the diverters, at the blind crossings of the railway track, at the junctions of the rails, and so on. 


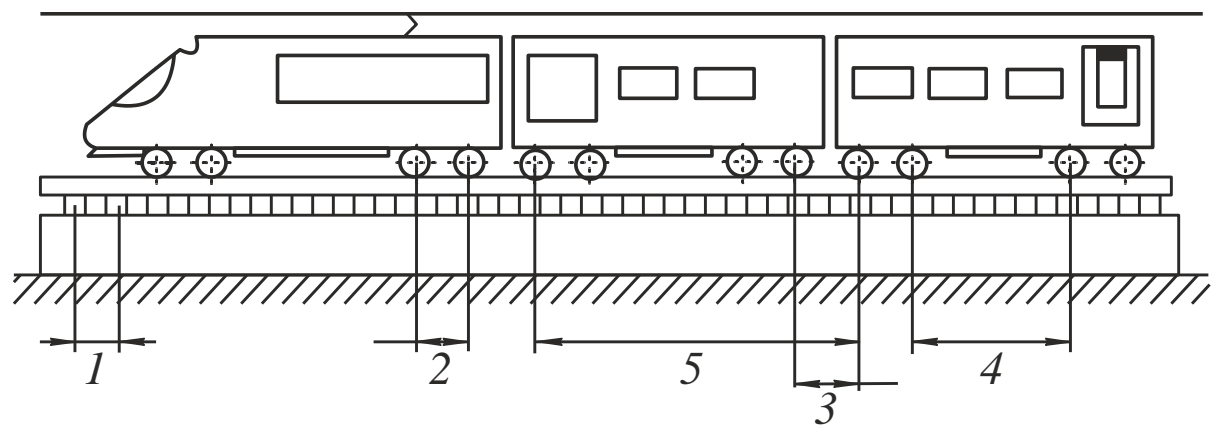

Fig. 1. - The causes of the excitation of periodic vibrations of a railway locomotive: 1 is the distance between the support elements of the railway track; 2 is the distance between the wheel pairs of the bogie; 3 is the distance between the adjacent bogies of adjacent railway cars; 4 is the distance between the bogies of a railway car; 5 is the distance between railway cars

The random vibrations are the noise emitted by the rattling objects (panes, lamps, conjugations of a shaft-hole with the loose fit and so on). The vibration is transmitted, being changed through the rail tracks on their support and further into the ground, the frame and the body of a locomotive, the surface roughness of a wheel rim and when riding the rail, causing at the same time the re-radiated noise. The re-radiated noise of the object of the exposure is observed in the frequency range from about 16 to $250 \mathrm{~Hz}$ in accordance with the Resolution. The description of the noises is quantitatively associated with certain difficulties, so they will not be considered.

When analyzing the vibration and the noise, it should be considered that the vibration sources, their pathways of the propagation and the objects of their effect depend on many factors, namely, according to the Resolution: the geometry of the rail track, the characteristics of the rolling stock (its length, a wheel profile, a wheel diameter, the roughness and surface defects when riding a wheel, the system of the wheel suspension, wheels with elastic elements and etc.), the characteristics of rails, elements of the rail track, and others. The vibration source, the pathway of the vibration propagation and the object of the effect are shown schematically in Fig. 2.

\section{The definition of the boundaries of the range of possible fluctuations of a railway locomotive}

The frequency of the periodic vibrations depends on the speed of a railway locomotive. Table 1 summarizes the possible oscillation frequencies depending on the speed of the movement (VM) applied to an electric locomotive VL series. The phenomena of interference, the vibration diffraction are not taken into account, i.e. the locomotive is considered as one rigid body.

A locomotive, ahead of the next train, experiences the vibrations generated not only by the train and by the railroad track, but the vibrations generated by the bogies of the driven railway cars. The vibration oscillation of each railway car is transmitted by the rails as through the waveguides with the velocity of the sound in metals $(\approx 22000 \mathrm{~km} / \mathrm{h})$. The vibration oscillation caused by the deflection of the rails in the intervals between the sleepers, results in the formation of a surface (Rayleigh) wave on the ground surface. These waves formed by the railway cars of the rolling stock, 
provided the hard ground, can catch up and overtake a locomotive, that in turn can result in the change of the oscillation spectrum of the rolling stock as well as of the locomotive. If the high-speed train moves along the rail track, provided the soft ground, then, the velocity of its movement can exceed the speed of the propagation of a surface (Rayleigh) wave in the ground. This creates a high level of vibration, just as the flight of a supersonic aircraft is accompanied by the sonic boom (based on the Solution).

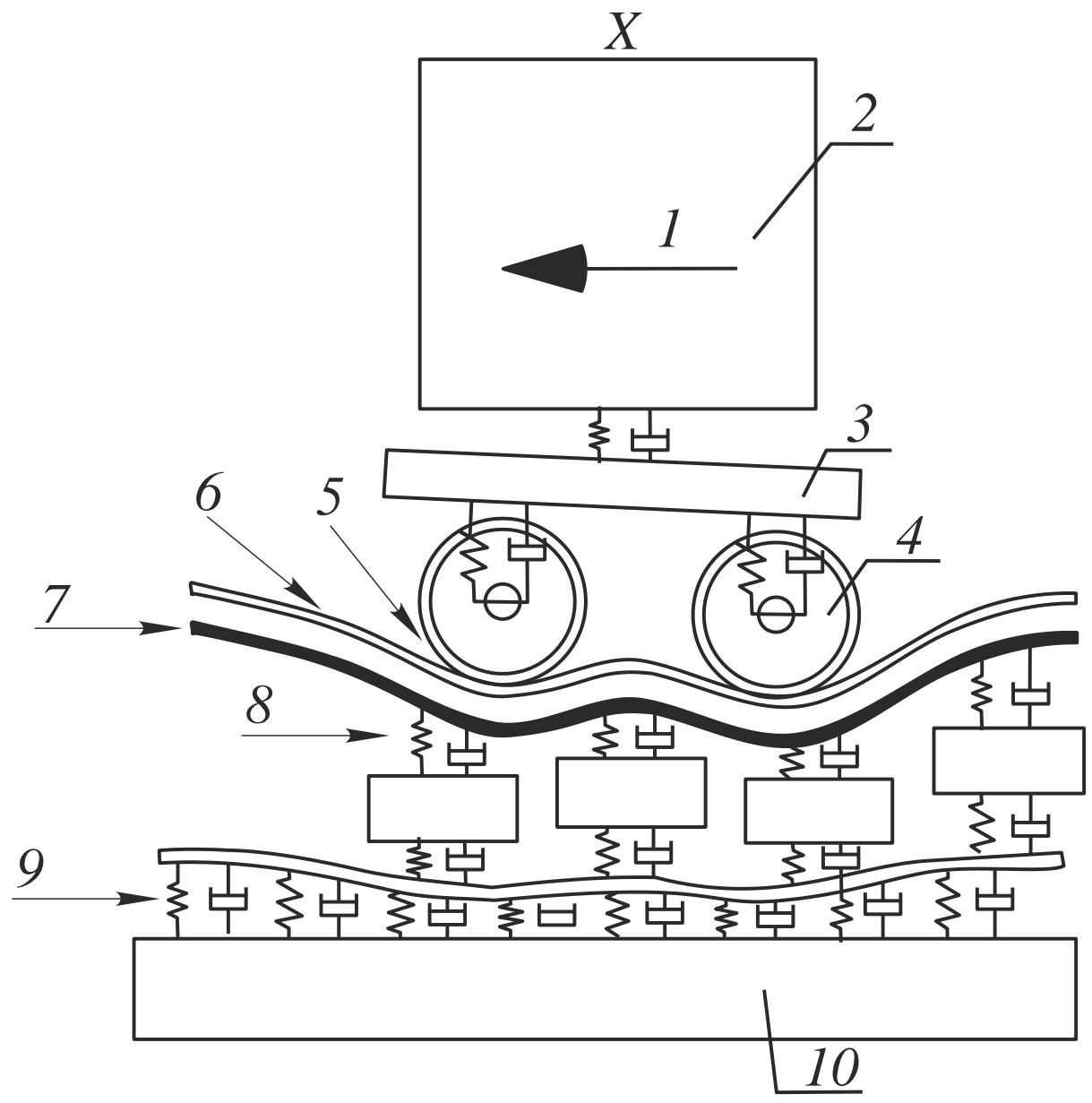

Fig. 2. - The description of the vibration source: 1 is the speed of movement; 2 is the part of the mass of the body; 3 is the part of the mass of the bogie; 4 is the unsprung weight; 5 is the roughness of the surface of the wheel rim; 6 is the roughness of the surface when riding the rail; 7 is the impedance of the rail; 8 is a model of the system "rail-wheel"; 9 is a model of the system "base - rail"; 10 is impedance of the ground

Thus, the vibrations of the entire rolling stock participate in the formation of the oscillation spectrum of the locomotive vibrations. The range of the locomotive 
vibration spectrum in this case can only change as a result of the dispersion of various vibration sources formed by railway cars of the rolling stock. In the paper we assume that there is no dispersion of the oscillation vibration.

Table 1. The frequencies of the potential oscillation of an electric locomotive

\begin{tabular}{|c|c|c|c|c|c|}
\hline $\begin{array}{l}\text { Name of parameters of } \\
\text { railway track and } \\
\text { suspension of an electric } \\
\text { locomotive }\end{array}$ & $\begin{array}{l}\text { Geometric dimensions } \\
\text { and sources of } \\
\text { information }\end{array}$ & $\begin{array}{l}\text { Speed of move- } \\
\text { ment of an elec- } \\
\text { tric locomotive, } \\
\mathrm{km} / \text { hour }(\mathrm{m} / \mathrm{c})\end{array}$ & $\begin{array}{l}\text { Frequency } \\
\text { oscillation } \\
\mathrm{f}, \mathrm{Hz}\end{array}$ & $\begin{array}{l}\text { fMAX / fMIN, } \\
\mathrm{Hz}\end{array}$ & $\begin{array}{l}\text { [fMAX; } \\
\text { fMIN], Hz }\end{array}$ \\
\hline $\begin{array}{l}\text { Distance between support } \\
\text { elements of the track, m }\end{array}$ & $\begin{array}{l}0,501-0,632 \\
\text { (GOST R 51248-99; } \\
\text { GOST 78-2004; } \\
\text { GOST 9238-83; } \\
\text { GOST 10629-88, [1]) }\end{array}$ & \multirow{9}{*}{ 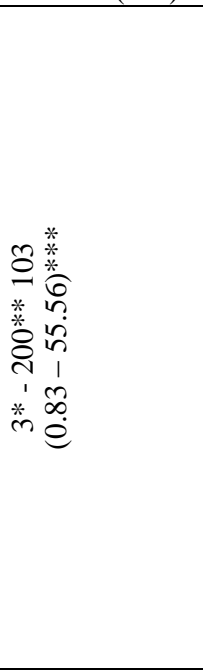 } & $\frac{V_{M}}{0,501-0,632}$ & $\begin{array}{l}1.31-1.66 / \\
87.91-110.9\end{array}$ & \multirow{9}{*}{$\begin{array}{l}0 \\
0 \\
\frac{1}{1} \\
\frac{8}{0} \\
0\end{array}$} \\
\hline \multirow{2}{*}{$\begin{array}{l}\text { Distance between wheel } \\
\text { pairs of the bogie, } m\end{array}$} & $1,85[2]$ & & $V_{M} / 1,85$ & $0.45-30.03$ & \\
\hline & $1,35[2]$ & & $V_{M} / 1,35$ & $0,61-41.16$ & \\
\hline $\begin{array}{l}\text { Distance between adjacent } \\
\text { bogies of adjacent railway } \\
\text { cars, } m\end{array}$ & $\begin{array}{l}5,72 \text { electric } \\
\text { locomotive VL8 [2] }\end{array}$ & & $V_{M} / 5,72$ & $0,15-9.71$ & \\
\hline $\begin{array}{l}\text { Distance between bogies of } \\
\text { a railway car, } m\end{array}$ & $\begin{array}{l}4,5 \text { electric } \\
\text { locomotive VL8 [2] }\end{array}$ & & $V_{M} / 4,5$ & $0.18-12.35$ & \\
\hline $\begin{array}{l}\text { Distance between railway } \\
\text { cars, } m\end{array}$ & $\begin{array}{l}\text { 162,2 electric } \\
\text { locomotive VL8 [2] }\end{array}$ & & $V_{M} / 162,2$ & $0,01-0,34$ & \\
\hline Length of rails, $\mathrm{m}$ & $\begin{array}{l}12,5 \\
\text { [GOST R 51045-97; } \\
\text { GOST R 51685-2000] }\end{array}$ & & $V_{M} / 12,5$ & $0,07-44.4$ & \\
\hline & $\begin{array}{l}25 \text { [GOST R 51045-97; } \\
\text { GOST R 51685-2000] }\end{array}$ & & $V_{M} / 25$ & $0.03-2.22$ & \\
\hline & $800 * * *$ (welded) & & $V_{M} / 800$ & $0.001-0.07$ & \\
\hline
\end{tabular}

* Minimum speed of a shunting locomotive;

** Maximum speed of an electric locomotive on the railroads of RF (Ch. Speed $200-200$ $\mathrm{km} / \mathrm{h}$ of the high speed train 165/166 Petersburg-Moscow)

*** Technical instructions on design, installation, maintenance and repair of continuous welded railroad. March 31, $2000 \mathrm{M}$ - Movement

\section{The light requirements to a searchlight of a railway locomotive}

A headlight of an electric locomotive VL series must meet certain requirements. A lamp should be installed along the longitudinal axis of the symmetry of a locomotive. The axial beam of the headlight should be directed parallel to the horizontal plane of the road. The nominal axial intensity of the lamp should be (6.4-9.6)-105 cd. The closed circuit of the lamp must provide the possibility of powering up the bright light, providing the nominal axial force of the light and the dim light, providing the power of the light within (0.7-1.2)·105 cd in accordance with GOST 12.2.056-81.

The test method for measuring the axial light intensity of the headlight is to determine the light intensity by measuring the light with simultaneous measuring the voltage of the light source in accordance with the regulations of 2000, agreed by the contact group 28/01/2010 V1.00, about the preservation of technical and interoperability of the rail system of the rail road of $1520 \mathrm{~mm}$ and $1435 \mathrm{~mm}$ at the border of the CIS and the EU, as well as in accordance with [3]. The measurement of the light intensity of the headlight is carried out when a photodetector is located along the axis of the pathway from the light at the distance that is greater than the distance 
of the formation of the light flow of the lamp. For the headlight used currently on the rolling stock, the distance of forming the light flow is not less than $20 \mathrm{~m}$ in accordance with the paragraph A.19.1 GOST 12.2.056-81, and also in accordance with [3].

To achieve the nominal axial force of the light of the headlight and to achieve the angles of ray scattering [3] in the vertical and horizontal planes $\sim 3^{\circ}$, it is necessary to focus the headlight in accordance with Annex 1 of the Rules of the technical operation of railways of RF. The light spot having the axial strength of 6.4-9.6 $10 \mathrm{~cd}$ is formed on a flat screen perpendicular to the horizon by the headlight spaced apart from the screen at $10 \mathrm{~m}$. The required orientation of the light spot on the screen is provided by the design of the headlight [4-7]. The operating experience of the headlight shows that the lamp SL (TU 16-87 IMFR 675000,003 W) $500 \mathrm{~W}$ and $50 \mathrm{~V}$ burns most frequently, and also a glass reflector with a diameter of $370 \mathrm{~mm}$ breaks, when installed behind the lamp SL. These failures could be caused by the vibration oscillations.

\section{The conditions for the determination of the natural frequencies of a solid model of the design of the searchlight of a locomotive}

To determine the natural frequencies of a headlight in the software environment ANSYS the 3D model is used that is obtained in [8]. In the solid model the screw connections (screws and bolts have been removed from the model) are not taken into account due to the lack of the computing power. The parameters of the finite element mesh on the surface of a solid model are selected automatically by the program (Fig. 3).

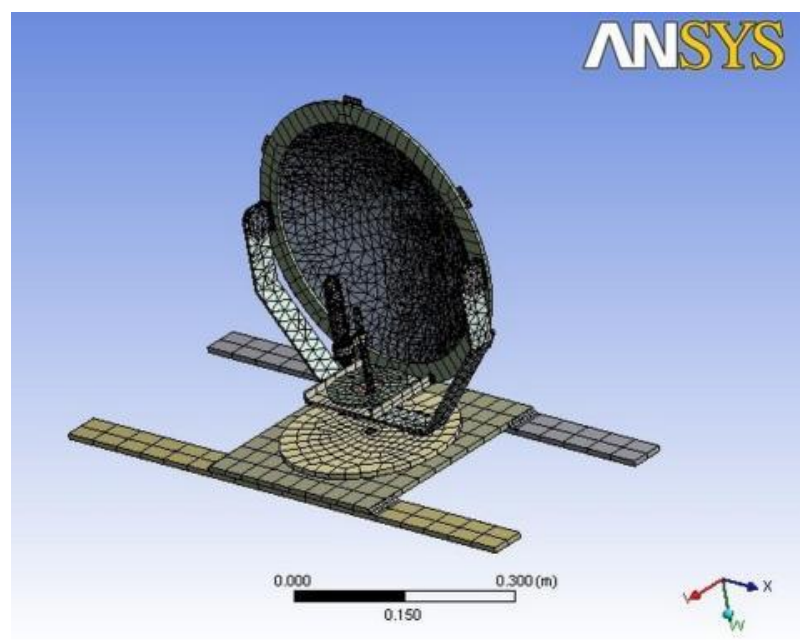

Fig. 3. - The finite element mesh on the surface of a solid model of a headlight

The requirements for modeling are defined by the rules of the computational experiments in the optics [9-17]. The conducted simulation shows that in the frequency range of the periodic vibrations (Table. 1), we have the greatest deformations of the glass reflector for the natural frequencies of 22.368 and 62.595 $46.49 \mathrm{~Hz}$. The oscillation frequency $f=46.49 \mathrm{~Hz}$ may correspond to the vibrations 
caused by the length of the rails $(25 \mathrm{~m})$, the distance between the wheel pairs of a bogie and the distance between the support elements of the railroad (slippers). At the frequency $f=95.998 \mathrm{~Hz}$ occurs the deformation of a glass bulb of the lamp SL, and there is no deformation of the glass reflector of the headlight.

a)

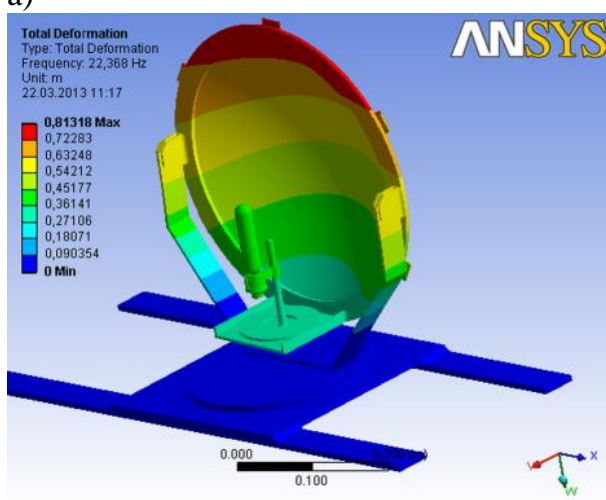

c)

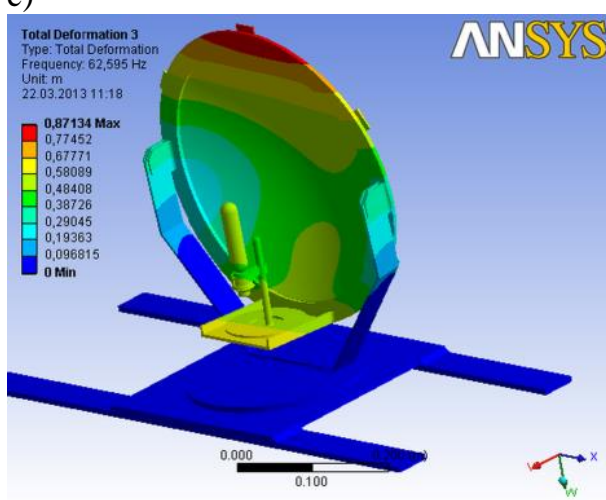

b)

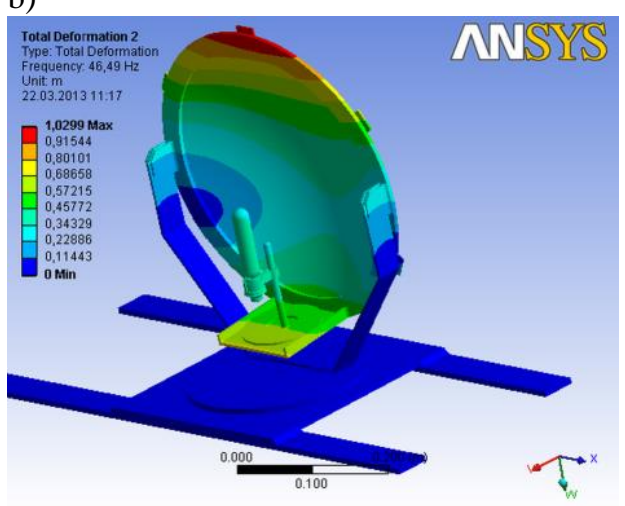

d)

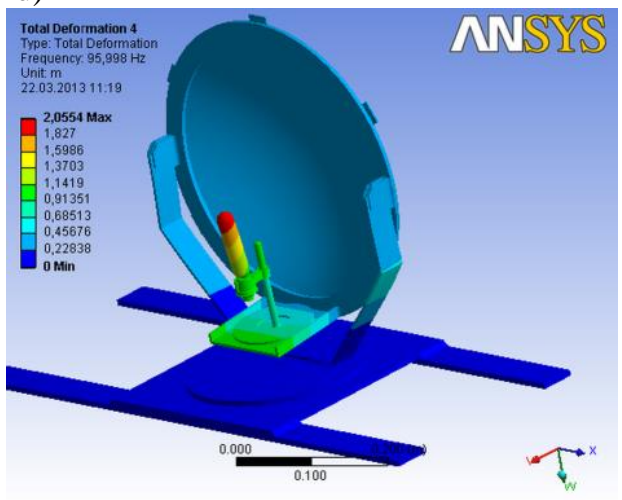

Fig. 4. - The oscillation of the design of a headlight at the natural frequencies: a) $\mathrm{f}=22.368 \mathrm{~Hz}$; b) $\mathrm{f}=46.49 \mathrm{~Hz}$; c) $\mathrm{f}=62.595 \mathrm{~Hz}$; d) $\mathrm{f}=95.998 \mathrm{~Hz}$

For the frequencies above the maximum frequency of the periodic vibrations $(f=110.9 \mathrm{~Hz}$ Tab. 1$)$, the maximum deformations are at the end of the glass bulb of the lamp SL. A glass reflector in this case is deformed slightly (Fig. 4).

\section{Conclusions}

1. The destruction of a glass reflector is in the range of the frequencies of the vibration oscillation [22.368 - 62.595] Hz.

2. The destruction of a glass lamp SL is at the frequencies greater than $95.998 \mathrm{~Hz}$.

3. The increase in the resource of the lamp SL can be achieved by changing the design of a headlight, namely by using the high-frequency dampers. 
a)

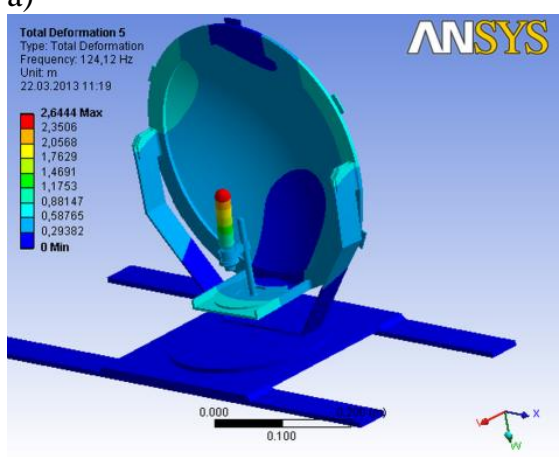

b)

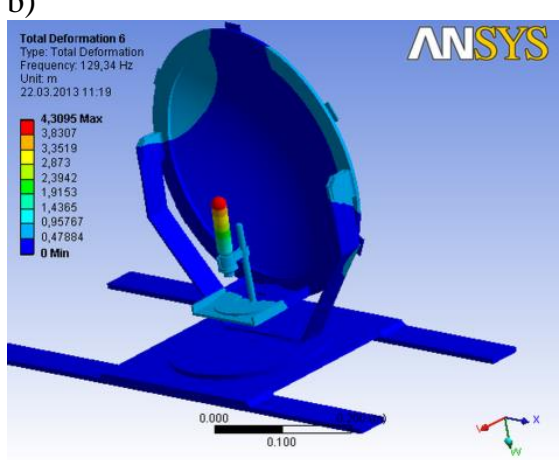

c)

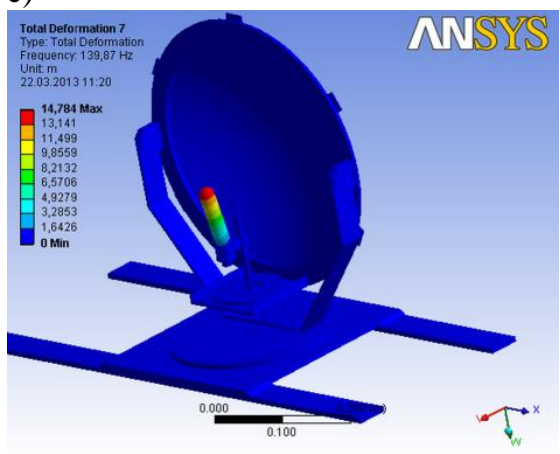

d)

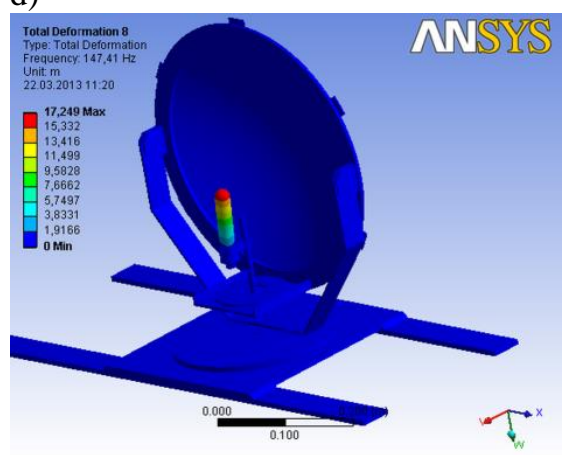

e)

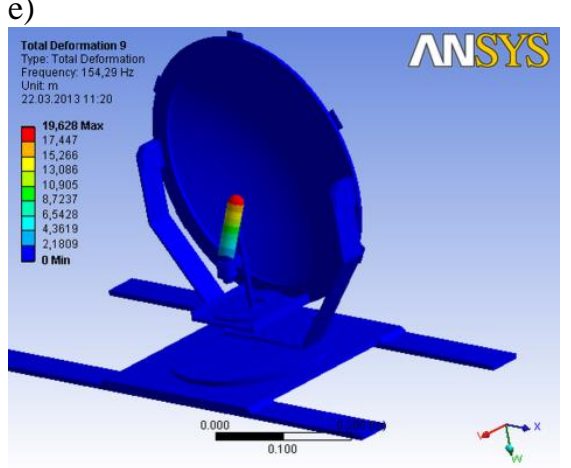

g)

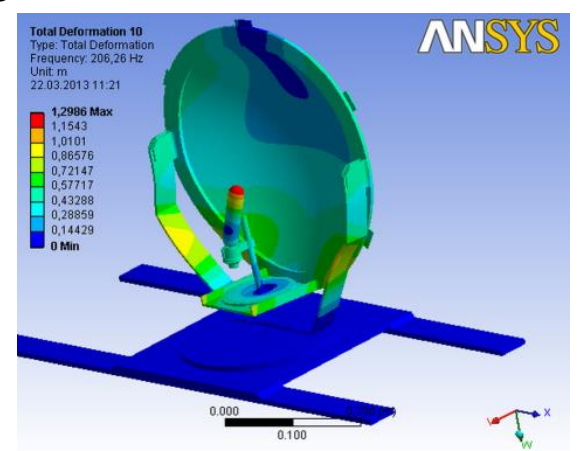

Fig. 5. - The oscillation of the design of a headlight at the natural frequencies: a $-f=22.368$ $\mathrm{Hz} ; \mathrm{b}-f=46.49 \mathrm{~Hz} ; \mathrm{c}-f=62.595 \mathrm{~Hz} ; \mathrm{d}-f=95.998 \mathrm{~Hz} ; \mathrm{e}-f=154.29 \mathrm{~Hz} ; \mathrm{g}-f=206.26 \mathrm{~Hz}$.

4. The substantial increase in the resource of a headlight can also be achieved by replacing an incandescent lamp by the high power light emitting diodes (LEDs) using new methods and the necessary software for designing such a lighting device [1824].

5. The presented results play an important role in the design [25-28] of hyperspectral remote sensing equipment feeling strong vibrations loads in the derivation of Earth's 
orbit. Also, these results will be useful for creating transport systems of computer vision [29-32], optical devices [33-36], components, and devices of diffractive nanophotonics [37-44].

\section{References}

1. Methods of assessing the impact of the rolling stock on the railroad under the terms of ensuring its reliability. Ed. Zhelnin GG. Moscow: "VNIIJT" Publisher; 2000. 38 p. [in Russian]

2. Pushkarev BA, Pozdnyakov LA, et al. Electric locomotive VL85: Operation instruction. Moscow: "Transport" Publisher, 1992. 480 p. [in Russian]

3. Kazanskiy NL, Kharitonov SI, Soifer VA, Volkov AV. Investigation of Lighting Devices Based on Diffractive Optical Elements. Optical Memory \& Neural Networks (Information Optics), 2000; 9(4): 301-312.

4. Kazanskiy NL, Kotlyar VV, Soifer VA. Computer-aided design of diffractive optical elements. Optical Engineering, 1994; 33(10): 3156-3166.

5. Golovashkin DL, Kasanskiy NL. Solving Diffractive Optics Problem using Graphics Processing Units. Optical Memory and Neural Networks (Information Optics), 2011; 20(2): 85-89.

6. Doskolovich LL, Golub MA, Kazanskiy NL, Khramov AG, Pavelyev VS, Seraphimovich PG, Soifer VA, Volotovskiy SG. Software on diffractive optics and computer generated holograms. Proceedings of SPIE, 1995; 2363: 278-284.

7. Doskolovich LL, Kazansky NL, Kharitonov SI, Soifer VA. A method of designing diffractive optical elements focusing into plane areas. Journal of Modern Optics, 1996; 43(7): 1423-1433.

8. Abulkhanov SR. The construction of an authentic 3-D model of a headlight of an electric locomotive. Bulletin SamGUPS, 2012; 3(17): 81-86.

9. Golub MA, Kazanskii NL, Sisakyan IN, Soifer VA, Kharitonov SI. Diffraction calculation for an optical element which focuses into a ring. Optoelectronics, Instrumentation and Data Processing, 1987; 6: 7-14.

10. Golub MA, Kazanskii NL, Sisakyan IN, Soifer VA. Computational experiment with plane optical elements. Optoelectronics, Instrumentation and Data Processing, 1988; 1: 7889.

11. Kazanskiy NL, Soifer VA. Diffraction investigation of geometric-optical focusators into segment. Optik - International Journal for Light and Electron Optics, 1994; 96(4): 158162.

12. Doskolovich LL, Kazanskiy NL, Soifer VA, Tzaregorodtzev AYe. Analysis of quasiperiodic and geometric optical solutions of the problem of focusing into an axial segment. Optik - International Journal for Light and Electron Optics, 1995; 101(2): 37-41.

13. Doskolovich LL, Kazanskiy NL, Soifer VA, Perlo P, Repetto P. Design of DOEs for wavelength division and focusing. Journal of Modern Optics, 2005; 52(6): 917-926. doi:10.1080/09500340512331313953.

14. Golovashkin DL, Kazanskiy NL. Mesh Domain Decomposition in the Finite-Difference Solution of Maxwell's Equations. Optical Memory \& Neural Networks (Information Optics), 2009; 18(3): 203-211.

15. Khonina SN, Kazanskii NL, Ustinov AV, Volotovskii SG. The lensacon: nonparaxial effects. Journal of Optical Technology, 2011; 78(11): 724-729. doi: 10.1364/JOT.78.000724 
16. Khonina SN, Kazanskiy NL, Volotovsky SG. Influence of Vortex Transmission Phase Function on Intensity Distribution in the Focal Area of High-Aperture Focusing System. Optical Memory and Neural Networks (Information Optics), 2011; 20(1): 23-42. doi: 10.3103/S1060992X11010024.

17. Kazanskiy NL. Research \& Education Center of Diffractive Optics. Proceedings of SPIE, 2012; 8410: 84100R. doi: 10.1117/12.923233.

18. Doskolovich LL, Kazanskiy NL, Soifer VA, Kharitonov SI, Perlo P. A DOE to form a line-shaped directivity diagram. Journal of Modern Optics, 2004; 51(13): 1999-2005.

19. Doskolovich LL, Kazanskiy NL, Kharitonov SI, Perlo P, Bernard S. Designing reflectors to generate a line-shaped directivity diagram. Journal of Modern Optics, 2005; 52(11): 1529-1536.

20. Doskolovich LL, Kazanskiy NL, Bernard S. Designing a mirror to form a line-shaped directivity diagram. Journal of Modern Optics, 2007; 54(4): 589-597.

21. Kazanskiy N, Skidanov R. Binary beam splitter. Applied Optics, 2012; 51(14): 2672-2677. doi: 10.1364/AO.51.002672.

22. Aslanov ER, Doskolovich LL, Moiseev MA, Bezus EA, Kazanskiy NL. Design of an optical element forming an axial line segment for efficient LED lighting systems. Optics Express, 2013; 21(23). 28651-28656.

23. Doskolovich LL, Dmitriev AYu, Moiseev MA, Kazanskiy NL. Analytical design of refractive optical elements generating one-parameter intensity distributions. J. Opt. Soc. Am. A, 2014; 31(11): 2538-2544. doi: 10.1364/JOSAA.31.002538.

24. Doskolovich LL, Kazanskiy NL, Perlo P, Repetto P, Soifer VA. Direct two-dimensional calculation of binary DOEs using a non-binary series expression approach. International Journal of Optoelectronics, 1996; 10(4): 243-249.

25. Kazanskiy NL, Kharitonov SI, Khonina SN, Volotovskiy SG, Strelkov YuS. Simulation of hyperspectrometer on spectral linear variable filters. Computer Optics, 2014; 38(2): 256-270. [in Russian]

26. Kazanskiy NL, Kharitonov SI, Karsakov AV, Khonina SN. Modeling action of a hyperspectrometer based on the offner scheme within geometric optics. Computer Optics, 2014; 38(2); 271-280. [in Russian]

27. Kazanskiy NL, Kharitonov SI, Khonina SN. Simulation of a hyperspectrometer based on linear spectral filters using vector Bessel beams. Computer Optics, 2014; 38(4): 770776. [in Russian]

28. Kazanskiy NL, Kharitonov SI, Doskolovich LL, Pavelyev AV. Modeling the performance of a spaceborne hyperspectrometer based on the Offner scheme. Computer Optics, 2015; 39(1): 70-76. [in Russian]

29. Kazanskiy NL, Popov SB. Machine Vision System for Singularity Detection in Monitoring the Long Process. Optical Memory and Neural Networks (Information Optics), 2010; 19(1): 23-30. doi:10.3103/S1060992X10010042.

30. Kazanskiy NL, Popov SB. The distributed vision system of the registration of the railway train. Computer Optics, 2012; 36(3): 419-428. [in Russian]

31. Kazanskii NL, Khonina SN, Skidanov RV, Morozov AA, Kharitonov SI, Volotovskiy SG. Formation of images using multilevel diffractive lens. Computer Optics, 2014; 38(3): 425-434. [in Russian]

32. Kazanskiy NL, Popov SB. Integrated Design Technology for Computer Vision Systems in Railway Transportation. Pattern Recognition and Image Analysis, 2015; 25(2): 215-219. doi: $10.1134 / \mathrm{S} 1054661815020133$. 
33. Karpeev SV, Pavelyev VS, Khonina SN, Kazanskiy NL, Gavrilov AV, Eropolov VA. Fibre sensors based on transverse mode selection. Journal of Modern Optics, 2007; 54(6): 833-844. doi:10.1080/09500340601066125.

34. Doskolovich LL, Kazanskiy NL, Khonina SN, Skidanov RV, Heikkila N, Siitonen S, Turunen J. Design and investigation of color separation diffraction gratings. Applied Optics, 2007; 46(15): 2825-2830.

35. Borodin SA, Volkov AV, Kazanski NL. Device for analyzing nanoroughness and contamination on a substrate from the dynamic state of a liquid drop deposited on its surface. Journal of Optical Technology, 2009; 76(7): 408-412.

36. Khonina SN, Savelyev DA, Kazanskiy NL. Vortex phase elements as detectors of polarization state. Optics Express, 2015; 23(14): 17845-17859. doi: 10.1364/OE.23.017845.

37. Kazanskiy NL, Serafimovich PG, Khonina SN. Harnessing the Guided-Mode Resonance to Design Nanooptical Transmission Spectral Filters. Optical Memory and Neural Networks (Information Optics), 2010; 19(4): 318-324. doi: 10.3103/S1060992X10040090.

38. Bezus EA, Doskolovich LLKazanskiy NL. Scattering suppression in plasmonic optics using a simple two-layer dielectric structure. Applied Physics Letters, 2011; 98(22): 221108. 3 pp. doi: 10.1063/1.3597620.

39. Bezus EA, Doskolovich LL, Kazanskiy NL, Soifer VA. Scattering in elements of plasmon optics suppressed by two-layer dielectric structures. Technical Physics Letters, 2011; 37(12): 1091-1095.

40. Kazanskiy NL, Serafimovich PG, Khonina SN. Use of photonic crystal cavities for temporal differentiation of optical signals. Optics Letters, 2013; 38(7): 1149-1151.

41. Kazanskiy NL, Serafimovich PG. Cloud Computing for Nanophotonic Simulations. Lecture Notes in Computer Science, 2013; 7715: 54-67.

42. Bezus EA, Doskolovich LL, Kazanskiy NL. Low-scattering surface plasmon refraction with isotropic materials. Optics Express, 2014; 22(11): 13547-13554. doi: 10.1364/OE.22.013547.

43. Kazanskiy NL, Serafimovich PG. Coupled-resonator optical waveguides for temporal integration of optical signals. Optics Express, 2014; 22(11): 14004-14013. doi: 10.1364/OE.22.014004.

44. Soifer VA. Diffractive Nanophotonics and Advanced Information Technologies. Herald of the Russian Academy of Sciences, 2014; 84(1): 9-18. doi: 10.1134/S1019331614010067. 